\title{
The Impact of Changes in Environmental Conditions on Organic Acid Production by Commercial Wine Yeast Strains
}

\author{
B.S. Chidi, F.F. Bauer, D. Rossouw* \\ Institute for Wine Biotechnology, Department of Oenology and Viticulture, Private Bag X1, Stellenbosch University, \\ Stellenbosch, 7600, South Africa
}

Submitted for publication: January 2018

Accepted for publication: June 2018

Key words: Fermentation, organic acids, wine yeast, environmental factors, temperature, acidity

\begin{abstract}
Acidity is one of the primary sensory elements in wine, and the balance of sugar and acidity is probably the strongest element affecting wine appreciation. However, little is known about how yeast strains and fermentation conditions will affect the production of fermentation-derived acids, including acetic, succinic and pyruvic acid. This study employs a multifactorial experimental design to provide a better understanding of how individual or simultaneous changes in environmental parameters such as pH, sugar and temperature influence the production of individual organic acids during fermentation in several yeast strains in synthetic must. Certain changes in environmental factors led to conserved trends between strains and treatments. Strains produced higher succinic acid levels when temperature was increased. Significant strain-dependent differences were observed when sugar concentrations were varied for both strains: the combinatorial impact of high initial sugars and fermentation temperature was more pronounced when increased pyruvic acid production was observed in yeast strain VIN13. On the other hand, while combinatorial influences are evident, higher sugar fermentation settings were largely characterised by high acetic acid concentrations for both strains. It is clear that simultaneous changes in sugar, $\mathrm{pH}$ and temperature affect organic acid trends in a variable manner, depending on the particular combination of environmental parameters and yeast strain. The study provides valuable information regarding the manner in which initial must parameters and environmental conditions throughout fermentation may affect wine acidity. Since many of these parameters can be controlled at least in part during the winemaking process, the data provide important background information for oenological strategies that aim to optimise the acid balance of wines.
\end{abstract}

\section{INTRODUCTION}

The sensory perception of wine is dependent on the interplay between alcohol, sugars and acids, as well as many other secondary grape- and fermentation-derived metabolites such as higher alcohols and esters. Grape-derived acids such as citric, tartaric and malic acid are dominant in grape juice and in wine, but fermentation-derived acids such as pyruvic, acetic and succinic acid are also present in the finished wines. The sensory effects of acids have been reasonably well documented, with a sour and sharp taste associated with too much acidity, while low-acidity wines may be perceived as flat and generally display a less well-defined flavour profile (Mato et al., 2005). All acids will add to this general perception of acidity, and each acid also has an additional and acid-specific impact on the taste of wine (Shiraishi et al., 2010). Acetic acid, for example, is associated with a perception of vinegar, while succinic acid may generate a metallic character. The monitoring of certain acids during fermentation enables winemakers to effectively control aspects of alcoholic and malolactic fermentation, as well as wine ageing (Bisson et al., 2002). However, there is limited information regarding the manner in which fermentation conditions affect the metabolism of both grape- and yeastderived acids under winemaking conditions.

Several factors that individually influence the level and production of organic acids during fermentation have been identified in the past. Such factors include yeast and bacterial strains (wild or inoculated), fermentation temperature, initial sugar levels and $\mathrm{pH}$. Importantly, most of these factors can be managed at least in part by winemakers during fermentation, and a better understanding of their role(s) and the synergistic effects between these factors may therefore provide better tools for the management of fermentation and wine acidity (Lafon-Lafourcade, 1983; Lambrechts \& Pretorius, 2000; Agarwal et al., 2007; Kamzolova et al., 2009).

The influence of temperature, sugar levels and $\mathrm{pH}$ (all individually) on succinic acid have been elucidated relatively well (Thoukis et al., 1965; Shimazu \& Watanabe, 1981; Aragon et al., 1998; Torija et al., 2001). High levels of

*Corresponding author: E-mail address: debra@sun.ac.za [Tel.: +2721 808 4346; Fax: +2721 80837711$]$

Acknowledgments: The project was supported by Winetech and a SARChI research grant from the National Research Council 
succinic acid have been linked to high initial fermentation $\mathrm{pH}$ (Thoukis et al., 1965) and low fermentation temperature in rice wine (Liu et al., 2014). In most cases, aeration during fermentation increases the production of succinic acid. This effect has been ascribed to an increase in the levels or activity of enzymes of the TCA cycle, of which succinic acid is an intermediate (Boulton et al., 1996).

The production of acetic acid is influenced by the yeast strain (Shimazu \& Watanabe, 1981; Erasmus et al., 2004; Orlic et al., 2010), initial sugar (Remize et al., 1999), pH and physical factors such as temperature (Ribereau-Gayon et al., 2006; Beltran et al., 2008). The influence of high sugar levels (above 32 Brix) in ice wine (Pigeau \& Inglis, 2005; Pigeau et al., 2007) and botrytised wine (Bely et al., 2005) in terms of increasing acetic acid production has also been noted previously. Significant interactions between strains, incubation temperature and agitation time have also been reported (Fleet \& Heard, 1992).

By comparison, relatively little is known regarding the factors that affect pyruvic acid concentrations during fermentation. Several studies have noted higher pyruvic acid levels when the $\mathrm{pH}$ of the must was increased (Rankine, 1967; Samuelov, 1988). Furthermore, the degree of aeration and the sugar content of the grape juice have been reported to influence pyruvic acid concentrations (Lee et al., 1999).

While different fermentation parameters have been reported to significantly affect acid production, no studies have been dedicated to understanding the combined impacts of these parameters on yeast-derived wine acids. The current study explores the multifactorial interaction of $\mathrm{pH}$, temperature and sugar content under fermentative conditions. A pairwise-based evaluation of changes in organic acid concentrations across fermentation conditions enabled us to understand the organic acid profile of the wines. The data contribute to our understanding of the integrated effects of these factors in fermentations conducted with different commercial wine yeast strains.

\section{MATERIALS AND METHODS}

\section{Strains, media and culture conditions}

Two commercially available wine yeast strains were selected based on their divergent fermentation properties (Rossouw et al., 2008). These $S$. cerevisiae strains are all used for industrial wine fermentations. Yeast cells were cultivated at $30^{\circ} \mathrm{C}$ in a rich, complex YPD synthetic medium $(1 \%$ yeast extract, Biolab, South Africa; $2 \%$ peptone, Fluka, Germany; and $2 \%$ dextrose, Sigma, Germany). The solid medium was supplemented with $2 \%$ agar (Biolab, South Africa). Yeast cultures were grown in $50 \mathrm{ml}$ shake flasks on YPD at $30^{\circ} \mathrm{C}$ and $250 \mathrm{rpm}$. These cultures were harvested by centrifugation, washed with sterile distilled water and inoculated at an $\mathrm{OD}_{600}$ of 0.1 (i.e. a final cell density of approximately $10^{6} \mathrm{cfu} \cdot \mathrm{ml}^{-1}$ ).

\section{Fermentation conditions and the experimental design}

Fermentation experiments were carried out in synthetic must, MS300, which approximates a natural must as previously described (Bely et al., 1990). The medium contained hexoses (equivalent amounts of glucose and fructose) of 150, 200 and $250 \mathrm{~g} / \mathrm{L}$, and temperatures were set at either 15,25 or $30^{\circ} \mathrm{C}$, while $\mathrm{pH}$ settings of $3.0,3.5$ or 4.0 were used. Due to the complex nature of our treatment combinations and variables, we adopted a Box-Behnken design (Box \& Behnken, 1960). We then omitted a few extreme settings (i.e. sugars greater than $250 \mathrm{~g} / \mathrm{L}$ and less than $150 \mathrm{~g} / \mathrm{L}, \mathrm{pH}$ greater than 4.0 and lower than 3 , temperature greater than $30^{\circ} \mathrm{C}$ and lower than $15^{\circ} \mathrm{C}$ ), which would obviously have resulted in stuck fermentations, and opted for all settings that are aligned with conditions relevant to winemakers. Fermentations were carried out under strict anaerobic conditions in $250 \mathrm{ml}$ Erlenmeyer flasks (containing $100 \mathrm{ml}$ of the medium). Two wine yeast strains (BM45 and VIN13) were inoculated to ferment under different experimentally designed conditions. Fermentations were completed by day 14 (a stage when the residual sugar was less than $5 \mathrm{~g} / \mathrm{L}$ ), and the samples were withdrawn anaerobically using a sampling port connected to a $0.22 \mu \mathrm{M}$ filter and syringe. All fermentations were carried out in triplicate. Cell propagation (i.e. growth) was determined spectrophotometrically (PowerwaveX, Bio-Tek Instruments) by measuring the optical density (at $600 \mathrm{~nm}$ ) of $200 \mu \mathrm{l}$ samples of the suspensions during fermentation at two-day intervals. Weight loss was likewise monitored at an interval of two days, while samples were collected on days 2, 5 and 14 for chemical analysis.

\section{Chemical analysis}

Culture supernatants were analysed for glucose, fructose, glycerol and ethanol by high performance liquid chromatography (HPLC) on an AMINEX HPX-87H ion exchange column at $55^{\circ} \mathrm{C}$ using $5 \mathrm{mM} \mathrm{H}_{2} \mathrm{SO}_{4}$ as the mobile phase at a flow rate of $0.5 \mathrm{ml} / \mathrm{min}$. Agilent RID and UV detectors were used for detection and quantification. Analyses were carried out using the HP Chemstation software package (Eyeghe-Bickong et al., 2012).

An improved capillary electrophoresis (CE) method, adapted from Soga and Ross (1997), was used to analyse and quantify organic acid contents in synthetic must (MS300). High performance capillary electrophoresis (HPCE) was also used, with a Hewlett-Packard G1600A HP3DCE system (Agilent Technologies, Waldbronn, Germany) fitted with a built-in photodiode array detector. HP3D Chemstation software was used for system control, data control and data handling. Samples were diluted with a $5 \mathrm{mM}$ morpholino ethane-sulphonic acid (MES) buffer $(\mathrm{pH}=6.20)$, which also contained $0.5 \mathrm{mM}$ sodium formate as an internal standard, and $10 \mathrm{mg} / \mathrm{L}$ sodium azide. The separation electrolyte $(\mathrm{pH}$ $=5.60$ ) consisted of $20 \mathrm{mM}$ pyridine-2,6-dicarboxylic acid (PDC), $0.5 \mathrm{mM}$ cetyltrimethylammonium bromide (CTAB) and $20 \%$ acetonitrile. Electrophoresis was carried out at $10^{\circ} \mathrm{C}$ in a fused-silica capillary column with an internal diameter of 50 microns, and a total length of $91.5 \mathrm{~cm}(60.0 \mathrm{~cm}$ effective length; Agilent Technologies, Germany). The column was separated at $-10 \mathrm{kV}$. Between each separation series, the capillary was automatically rinsed with $0.1 \mathrm{~mol} / 1 \mathrm{NaOH}$ for $5 \mathrm{~min}$, with water for $2 \mathrm{~min}$ and with running buffer for 5 min. Approximately $16 \mathrm{~nL}$ of sample was injected into the column by applying pressure (50 mbar) at the inlet side of the capillary. A small amount of separation electrolyte $(\sim 2 \mathrm{~nL})$ was injected into the column directly afterwards. The electric potential was ramped from zero to $-25 \mathrm{kV}$ within half a minute and then kept constant at $-25 \mathrm{kV}$ for the 
remainder of each run. Absorbance detection at $210 \mathrm{~nm}$ was used throughout the experiments.

\section{Statistical analysis of colour intensity}

Analysis of variance (ANOVA) was performed to compare organic acid levels produced by the VIN13 and BM45 strains at different fermentation setups. For significance tests, 95\% confidence intervals were calculated. This was done using STATISTICA 64 software. Cytoscape (Shannon et al., 2003) was used to generate the colour intensities of paired fermentation conditions. The ratio of the organic acid levels in the selected fermentation conditions was calculated for each organic acid produced, and then imported by using table import version 0.7 of Cytoscape and further integrated for visualisation.

\section{RESULTS}

The influence of environmental parameters on yeast growth

Fermentations in the different synthetic musts were monitored until weight loss ceased (Fig. 1). The growth of both VIN13 and BM45 followed similar trends for the different fermentation conditions, although the growth rates and final biomass formation differed in some cases. These observations suggest that commercial wine yeast ferments and grows comfortably over a wide range of $\mathrm{pH}$, temperature and sugar levels. As expected, the fermentations were faster at higher fermentation temperatures. The effect of the must sugar content on yeast growth and fermentation kinetics was equally consistent with expectations: Higher initial sugar concentrations resulted in increased final biomass (Fig. 1C and 1D).

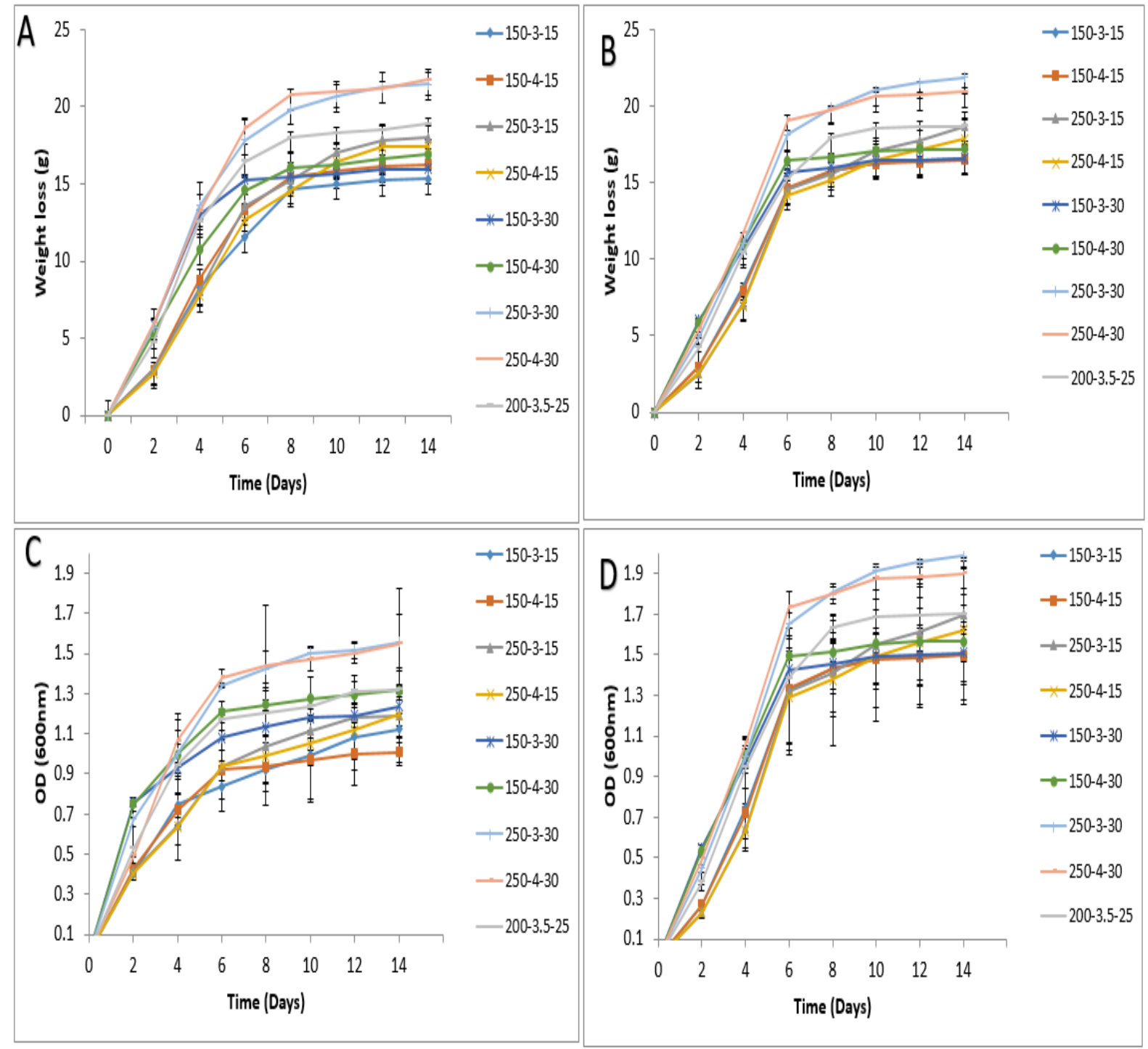

FIGURE

Fermentation rates of VIN13 (A) and BM45 (B), and growth rates of VIN13 (C) and BM45 (D) under different must composition and environmental conditions, i.e. sugars $(150,200$ and $250 \mathrm{~g} / \mathrm{L}), \mathrm{pH}(3.0,3.5$ and 4.0$)$ and temperature $\left(15,25\right.$ and $\left.30^{\circ} \mathrm{C}\right)$. Results are the average of three biological repeats \pm standard deviation. 
The impact of environmental factors on organic acid profiles

\section{Pyruvic acid}

The groupings in Table 1 clearly show those factors that resulted in the most significant increase (as identified by higher intensity of red colour and significant letter distinctions of acid concentrations) in pyruvic acid production by VIN13 (Table 1a) as (i) changes in temperature (from 15 to $30^{\circ} \mathrm{C}$ ) when other parameters such as sugar $(250 \mathrm{~g} / \mathrm{L})$ and $\mathrm{pH}(4)$ were constant (i.e. 0.00 to $0.39 \mathrm{~g} / \mathrm{L}$ ); (ii) changes in sugar (from 150 to $250 \mathrm{~g} / \mathrm{L}$ ) when temperature $\left(30^{\circ} \mathrm{C}\right)$ and $\mathrm{pH}$ (4) were constant (i.e. 0.00 to $0.39 \mathrm{~g} / \mathrm{L}$ ); (iii) simultaneous changes in sugar content (from 150 to $200 \mathrm{~g} / \mathrm{L}$ ), $\mathrm{pH}$ (from 4 to 3.5) and temperature (from 30 to $25^{\circ} \mathrm{C}$ ) (i.e. 0.00 to $0.37 \mathrm{~g} / \mathrm{L}$ ); (iv) simultaneous changes in sugar content (from 250 to 200 $\mathrm{g} / \mathrm{L}$ ), $\mathrm{pH}$ (4 to 3.5 ) and temperature (from 15 to $25^{\circ} \mathrm{C}$ ) (i.e. 0.00 to $0.37 \mathrm{~g} / \mathrm{L})$; and $(\mathrm{v})$ simultaneous changes in sugar (150 to $200 \mathrm{~g} / \mathrm{L}), \mathrm{pH}$ (4 to 3.5$)$ and temperature $\left(15\right.$ to $\left.25^{\circ} \mathrm{C}\right)$ (i.e. 0.00 to $0.37 \mathrm{~g} / \mathrm{L}$ ). While these environmental changes resulted in changes in the pyruvic acid profiles of VIN13, a slightly different pattern was observed for the BM45 strain (Table 1b). For this strain, pyruvic acid concentrations were mainly driven by changes in fermentation temperature (from 15 to $30^{\circ} \mathrm{C}$ ), $\mathrm{pH}$ (3 to 3.5 ) and sugar (150 to $200 \mathrm{~g} / \mathrm{L}$ ).

This highlights the importance of strain identity and fermentation parameters on organic acid profiles of the wines. While for a given strain (such as VIN13) there are emerging trends with regards to organic acid impacts in the different conditions, these acid-condition relationships are not conserved across all strains, as BM45 behaved similarly but with slight organic acid profile and changes. Although some changes in the environmental conditions slightly (represented by low red colour intensity and significant letter distinctions of acid concentrations) increased pyruvic acid production by strain BM45, there was no prominent causalities between specific parameter changes and reductions in pyruvate production by this strain.

On the other hand, reduced pyruvic acid (as represented by high blue colour intensity and significant letter distinctions of acid concentrations) was observed in higher $\mathrm{pH}$ (4) settings of both VIN13 (Table 1a) and BM45 fermentations (Table 1b). This pattern was achieved regardless of changes of other factors such as fermentation temperature and initial sugar concentration of the must.

The results show that single and combinatorial changes to sugars and temperature led to the most pronounced effects on pyruvic acid production. These two factors, besides having a significant impact on acid production, can also be partly controlled from a winemaking perspective.

\section{Acetic acid}

In most cases, combinatorial changes to sugar, temperature and $\mathrm{pH}$ did not result in very large increases (red colour intensity) or decreases (blue colour intensity) in acetic acid concentrations at the end of fermentation. Higher $\mathrm{pH}$ and temperature (particularly in combination) appear to result

TABLE 1

Pairwise comparisons of environmental conditions and the impact on pyruvic acid production of VIN13 (A) and BM45 (B).

\begin{tabular}{|c|c|c|c|c|c|}
\hline \multicolumn{6}{|l|}{ A } \\
\hline$(250-4-15)$ & $(150-4-30)$ & $(150-4-30)$ & $(250-4-15)$ & $(150-4-15)$ & $(250-3-15)$ \\
\hline $0.00 \pm 0.000^{\mathrm{E}}$ & $0.00 \pm 0.000^{\mathrm{E}}$ & $0.00 \pm 0.000^{\mathrm{E}}$ & $0.00 \pm 0.000^{\mathrm{E}}$ & $0.00 \pm 0.000^{\mathrm{E}}$ & $0.24 \pm 0.016^{\mathrm{D}}$ \\
\hline vs & vs & vs & vs & $v S$ & $v S$ \\
\hline$(250-4-30)$ & $(250-4-30)$ & $(200-3.5-25)$ & $(200-3.5-25)$ & $(200-3.5-25)$ & $(200-3.5-25)$ \\
\hline $0.39 \pm 0.003^{\mathrm{A}}$ & $0.39 \pm 0.003^{\mathrm{A}}$ & $0.37 \pm 0.006^{\mathrm{A}}$ & $0.37 \pm 0.006^{\mathrm{A}}$ & $0.37 \pm 0.006^{\mathrm{A}}$ & $0.37 \pm 0.006^{\mathrm{A}}$ \\
\hline$(150-3-15)$ & $(150-3-15)$ & $(250-3-15)$ & $(150-3-30)$ & $(150-3-15)$ & $(250-4-30)$ \\
\hline $0.30 \pm 0.021^{\mathrm{C}}$ & $0.30 \pm 0.021^{C}$ & $0.24 \pm 0.016^{\mathrm{D}}$ & $0.34 \pm 0.039^{\mathrm{B}}$ & $0.30 \pm 0.021^{\mathrm{C}}$ & $0.39 \pm 0.003^{\mathrm{A}}$ \\
\hline$v s$ & $v s$ & $v s$ & vs & $v s$ & $v s$ \\
\hline$(200-3.5-25)$ & $(150-4-15)$ & $(250-4-15)$ & $(150-4-30)$ & $(250-3-15)$ & $(200-3.5-25)$ \\
\hline $0.37 \pm 0.006^{\mathrm{A}}$ & $0.00 \pm 0.000^{\mathrm{E}}$ & $0.00 \pm 0.000^{\mathrm{E}}$ & $0.00 \pm 0.000^{\mathrm{E}}$ & $0.24 \pm 0.016^{\mathrm{D}}$ & $0.37 \pm 0.006^{\mathrm{A}}$ \\
\hline \multicolumn{6}{|l|}{ B } \\
\hline$(250-4-15)$ & $(150-4-30)$ & $(150-4-30)$ & $(250-4-15)$ & $(150-4-15)$ & $(250-3-15)$ \\
\hline $0.82 \pm 0.009^{\mathrm{G}}$ & $1.00 \pm 0.028^{\mathrm{D}}$ & $1.00 \pm 0.028^{\mathrm{D}}$ & $0.82 \pm 0.009^{\mathrm{G}}$ & $1.13 \pm 0.006^{\mathrm{B}}$ & $0.95 \pm 0.019^{\mathrm{E}}$ \\
\hline$v s$ & $v s$ & $v s$ & vs & $v s$ & $v s$ \\
\hline$(250-4-30)$ & $(250-4-30)$ & $(200-3.5-25)$ & $(200-3.5-25)$ & $(200-3.5-25)$ & $(200-3.5-25)$ \\
\hline $0.91 \pm 0.012^{\mathrm{F}}$ & $0.91 \pm 0.012^{\mathrm{F}}$ & $1.00 \pm 0.005^{\mathrm{D}}$ & $1.00 \pm 0.005^{\mathrm{D}}$ & $1.00 \pm 0.005^{\mathrm{D}}$ & $1.00 \pm 0.005^{\mathrm{D}}$ \\
\hline$(150-3-15)$ & $(150-3-15)$ & $(250-3-15)$ & $(150-3-30)$ & $(150-3-15)$ & $(250-4-30)$ \\
\hline $0.76 \pm 0.001^{\mathrm{H}}$ & $0.76 \pm 0.001^{\mathrm{H}}$ & $0.95 \pm 0.019^{\mathrm{E}}$ & $1.67 \pm 0.025^{\mathrm{A}}$ & $0.76 \pm 0.001^{\mathrm{H}}$ & $0.91 \pm 0.012^{\mathrm{F}}$ \\
\hline$v S$ & $v s$ & $v s$ & $v s$ & $v s$ & $v s$ \\
\hline$(200-3.5-25)$ & $(150-4-15)$ & $(250-4-15)$ & $(150-4-30)$ & $(250-3-15)$ & $(200-3.5-25)$ \\
\hline $1.00 \pm 0.005^{\mathrm{D}}$ & $1.13 \pm 0.006^{\mathrm{B}}$ & $0.82 \pm 0.009^{\mathrm{G}}$ & $1.00 \pm 0.028^{\mathrm{D}}$ & $0.95 \pm 0.019^{\mathrm{E}}$ & $1.00 \pm 0.005^{\mathrm{D}}$ \\
\hline
\end{tabular}

Comparisons shown are only where the changes were significant $(\mathrm{p} \leq 0.05)$. The values in the table are means of organic acid concentrations $(\mathrm{g} / \mathrm{L})$ and standard deviation. Different uppercase superscript letters represent statistically significant differences in concentrations of the paired fermentation conditions. Paired fermentation conditions are sugars, $\mathrm{pH}$ and temperature (respectively in brackets). Those changes in fermentation conditions that resulted in increased pyruvic acid production are represented by red shading, while those that resulted in reduced production are represented by blue shading. The colour intensities represent the degree of variation between the two conditions. 
in the production of increased acetic acid levels, while the impact of sugar changes produced conflicting results, i.e. increased and decreased levels of acetic acid production (Table 2). In the case of acetic acid, the strain response to changing conditions was mostly similar for VIN13 (Table 2a) and BM45 (Table 2b). However, there were few notable instances where the affect of changes in parameters on acetic acid production was strain specific: (i) changes in $\mathrm{pH}$ (150_3_30 vs 150_4_30) slightly increased acetic acid production in VIN13 fermentations (from $0.21 \mathrm{~g} / \mathrm{L}$ to $0.22 \mathrm{~g} / \mathrm{L}$, Table $2 \mathrm{a}$ ), but the opposite was observed for BM45 (from 0.28 to $0.22 \mathrm{~g} / \mathrm{L}$, Table $2 \mathrm{~b}$ ). On the other hand, simultaneous changes in sugar (250 to $200 \mathrm{~g} / \mathrm{L}$ ), $\mathrm{pH}$ (4 to $3.5)$ and temperature $\left(30\right.$ to $\left.25^{\circ} \mathrm{C}\right)$ increased and decreased acetic acid production for VIN13 (from 0.26 to $0.19 \mathrm{~g} / \mathrm{L}$ ) and BM45 (from 0.25 to $0.027 \mathrm{~g} / \mathrm{L}$ ) respectively.

\section{Succinic acid}

As was the case with acetic acid production, acid-condition relationships were fairly conserved across strains for succinic acid. Although both strains responded similarly to most changes in environmental factors, higher succinic acid levels $(0.47 \mathrm{~g} / \mathrm{L})$ were mostly observed when higher initial sugars, $\mathrm{pH}$ and fermentation temperature were tested in BM45 fermentations (Table 3b). In contrast, the most significant reduction (from 0.42 to $0.34 \mathrm{~g} / \mathrm{L}$ ) was observed (as represented by the higher intensity of blue colour and significant letter distinctions of succinic acid concentrations) when higher $\mathrm{pH}$ (4) settings were employed, while sugar $(150 \mathrm{~g} / \mathrm{L})$ and temperature $\left(15^{\circ} \mathrm{C}\right)$ were kept constant in BM45 fermentations. However, for the VIN13 strain, the most significant reduction (from 0.93 to $0.77 \mathrm{~g} / \mathrm{L}$ ) in succinic acid concentrations was noted when the initial sugar of the must was increased from 150 to $250 \mathrm{~g} / \mathrm{L}$, while temperature $\left(30^{\circ} \mathrm{C}\right)$ and $\mathrm{pH}(3)$ remained unchanged (Table $\left.3 \mathrm{a}\right)$.

\section{DISCUSSION}

The impact of fermentation parameters on yeast growth Both yeast strains grew faster at higher fermentation temperatures, in line with expectations (Fleet \& Heard, 1992). In addition, the increased final biomass because of higher initial sugar content of the must was also expected due to increased carbon availability, which supports additional growth of the yeast regardless of other factors such as $\mathrm{pH}$ and temperature. While temperature clearly affects growth rate, particularly in the earlier stages of fermentation, the total sugar content is responsible for the final biomass attained. Previous studies have also highlighted the importance of temperature and sugar content of the must to yeast growth kinetics (Fleet \& Heard, 1992; Charoenchai et al., 1998; D'Amato et al., 2006).

While $\mathrm{pH}$ affects yeast growth, the combinatorial effects of $\mathrm{pH}$, temperature and sugar variations were evident during fermentation. Several studies have previously reported on the combined influence of temperature and $\mathrm{pH}$ on wine yeast strains (Gao \& Fleet 1998; Serra et al., 2005; Yalcin

TABLE 2

Pairwise comparisons of environmental conditions and the effect on acetic acid production of VIN13 (A) and BM45 (B).

\begin{tabular}{|c|c|c|c|c|c|}
\hline \multicolumn{6}{|l|}{$\overline{\mathbf{A}}$} \\
\hline$(250-4-15)$ & $(150-3-30)$ & $(250-3-30)$ & $(150-4-30)$ & $(150-3-30)$ & $(250-4-30)$ \\
\hline $0.21 \pm 0.006^{\mathrm{D}}$ & $0.21 \pm 0.006^{\mathrm{D}}$ & $0.23 \pm 0.001^{\mathrm{C}}$ & $0.22 \pm 0.007^{\mathrm{C}}$ & $0.21 \pm 0.006^{\mathrm{D}}$ & $0.26 \pm 0.002^{\mathrm{B}}$ \\
\hline$v s$ & $v s$ & $v s$ & $v s$ & $v s$ & $v s$ \\
\hline$(250-4-30)$ & $(250-3-30)$ & $(250-4-30)$ & $(250-4-30)$ & $(150-4-30)$ & $(200-3.5-25)$ \\
\hline $0.26 \pm 0.002^{\mathrm{B}}$ & $0.23 \pm 0.001^{\mathrm{C}}$ & $0.26 \pm 0.002^{\mathrm{B}}$ & $0.26 \pm 0.002^{\mathrm{B}}$ & $0.22 \pm 0.007^{\mathrm{C}}$ & $0.19 \pm 0.002^{\mathrm{E}}$ \\
\hline$(150-3-15)$ & $(150-3-15)$ & $(250-3-15)$ & $(250-3-30)$ & $(150-3-15)$ & $(150-3-15)$ \\
\hline $0.28 \pm 0.009^{\mathrm{A}}$ & $0.28 \pm 0.009^{\mathrm{A}}$ & $0.23 \pm 0.004^{\mathrm{C}}$ & $0.23 \pm 0.001^{\mathrm{C}}$ & $0.28 \pm 0.004^{\mathrm{A}}$ & $0.28 \pm 0.005^{\mathrm{A}}$ \\
\hline$v s$ & $v s$ & $v s$ & $v s$ & $v s$ & $v s$ \\
\hline$(200-3.5-25)$ & $(150-3-30)$ & $(200-3.5-25)$ & $(200-3.5-25)$ & $(150-4-15)$ & $(250-3-15)$ \\
\hline $0.19 \pm 0.002^{\mathrm{E}}$ & $0.21 \pm 0.006^{\mathrm{D}}$ & $0.19 \pm 0.002^{\mathrm{E}}$ & $0.19 \pm 0.002^{\mathrm{E}}$ & $0.23 \pm 0.01^{\mathrm{C}}$ & $0.23 \pm 0.004^{\mathrm{C}}$ \\
\hline \multicolumn{6}{|l|}{$\mathbf{B}$} \\
\hline$(250-4-15)$ & $(150-3-30)$ & $(250-3-30)$ & $(150-4-30)$ & $(150-3-30)$ & $(250-4-30)$ \\
\hline $0.26 \pm 0.001^{\mathrm{D}}$ & $0.28 \pm 0.002^{\mathrm{CD}}$ & $0.29 \pm 0.003^{\mathrm{B}}$ & $0.22 \pm 0.008^{\mathrm{E}}$ & $0.28 \pm 0.002^{\mathrm{D}}$ & $0.25 \pm 0.027^{\mathrm{D}}$ \\
\hline$v s$ & $v s$ & $v s$ & $v s$ & $v s$ & $v s$ \\
\hline$(250-4-30)$ & $(250-3-30)$ & $(250-4-30)$ & $(250-4-30)$ & $(150-4-30)$ & $(200-3.5-25)$ \\
\hline $0.25 \pm 0.027^{\mathrm{D}}$ & $0.29 \pm 0.003^{\mathrm{B}}$ & $0.25 \pm 0.027^{\mathrm{D}}$ & $0.25 \pm 0.027^{\mathrm{D}}$ & $0.22 \pm 0.008^{\mathrm{E}}$ & $0.27 \pm 0.016^{\mathrm{CD}}$ \\
\hline$(150-3-15)$ & $(150-3-15)$ & $(250-3-15)$ & $(250-3-30)$ & $(150-3-15)$ & $(150-3-15)$ \\
\hline $0.34 \pm 0.022^{\mathrm{A}}$ & $0.34 \pm 0.022^{\mathrm{A}}$ & $0.26 \pm 0.005^{\mathrm{D}}$ & $0.29 \pm 0.003^{\mathrm{B}}$ & $0.30 \pm 0.022^{\mathrm{A}}$ & $0.34 \pm 0.002^{\mathrm{A}}$ \\
\hline$v s$ & $v s$ & $v s$ & $v s$ & $v s$ & $v s$ \\
\hline$(200-3.5-25)$ & $(150-3-30)$ & $(200-3.5-25)$ & $(200-3.5-25)$ & $(150-4-15)$ & $(250-3-15)$ \\
\hline $0.27 \pm 0.016^{\mathrm{D}}$ & $0.28 \pm 0.002^{\mathrm{CD}}$ & $0.27 \pm 0.016^{\mathrm{CD}}$ & $0.27 \pm 0.016^{\mathrm{CD}}$ & $0.26 \pm 0.008^{C}$ & $0.26 \pm 0.005^{\mathrm{D}}$ \\
\hline
\end{tabular}

Comparisons shown are only where the changes were significant $(\mathrm{p} \leq 0.05)$. The values in the table are means of organic acid concentrations $(\mathrm{g} / \mathrm{L})$ and standard deviation. Different uppercase superscript letters represent statistically significant differences in concentrations of the paired fermentation conditions. Paired fermentation conditions are sugars, $\mathrm{pH}$ and temperature (respectively in brackets). Those changes in fermentation conditions that resulted in increased acetic acid production are represented by red shading, while those that resulted in reduced production are represented by blue shading. The colour intensities represent the degree of variation between two conditions. 
TABLE 3

Pairwise comparisons of environmental conditions and the impact on succinic acid production of VIN13 (A) and BM45 (B).

\begin{tabular}{|c|c|c|c|c|c|}
\hline \multicolumn{6}{|l|}{$\mathbf{A}$} \\
\hline$(150-3-15)$ & $(150-3-15)$ & $(150-3-15)$ & $(150-3-15)$ & $(250-4-15)$ & $(250-3-30)$ \\
\hline $0.69 \pm 0.010^{\mathrm{F}}$ & $0.69 \pm 0.010^{\mathrm{F}}$ & $0.69 \pm 0.010^{\mathrm{F}}$ & $0.69 \pm 0.010^{\mathrm{F}}$ & $0.78 \pm 0.012^{\mathrm{D}}$ & $0.77 \pm 0.007^{\mathrm{E}}$ \\
\hline$v s$ & $v s$ & $v s$ & $v s$ & $v s$ & $v S$ \\
\hline$(150-3-30)$ & $(150-4-15)$ & $(200-3.5-25)$ & $(250-3-15)$ & $(200-3.5-25)$ & $(250-4-30)$ \\
\hline $0.93 \pm 0.033^{\mathrm{A}}$ & $0.83 \pm 0.02^{\mathrm{B}}$ & $0.83 \pm 0.008^{\mathrm{B}}$ & $0.81 \pm 0.029^{C}$ & $0.83 \pm 0.008^{\mathrm{B}}$ & $0.85 \pm 0.010^{\mathrm{B}}$ \\
\hline$(250-3-30)$ & $(150-3-30)$ & $(150-3-30)$ & $(150-3-30)$ & $(150-4-15)$ & $(250-4-30)$ \\
\hline $0.77 \pm 0.007^{\mathrm{E}}$ & $0.93 \pm 0.03^{\mathrm{A}}$ & $0.93 \pm 0.033^{\mathrm{A}}$ & $0.93 \pm 0.033^{\mathrm{A}}$ & $0.83 \pm 0.025^{\mathrm{B}}$ & $0.85 \pm 0.010^{\mathrm{B}}$ \\
\hline$v S$ & $v s$ & $v s$ & $v S$ & $v s$ & $v s$ \\
\hline$(200-3.5-25)$ & $(250-3-30)$ & $(200-3.5-25)$ & $(150-4-30)$ & $(250-4-15)$ & $(200-3.5-25)$ \\
\hline $0.83 \pm 0.008^{\mathrm{B}}$ & $0.77 \pm 0.007^{\mathrm{E}}$ & $0.83 \pm 0.008^{C}$ & $0.83 \pm 0.026^{\mathrm{BC}}$ & $0.78 \pm 0.012^{\mathrm{D}}$ & $0.83 \pm 0.008^{\mathrm{C}}$ \\
\hline \multicolumn{6}{|l|}{ B } \\
\hline$(150-3-15)$ & $(150-3-15)$ & $(150-3-15)$ & $(150-3-15)$ & $(250-4-15)$ & $(250-3-30)$ \\
\hline $0.42 \pm 0.017^{\mathrm{C}}$ & $0.42 \pm 0.017^{\mathrm{C}}$ & $0.42 \pm 0.017^{\mathrm{C}}$ & $0.42 \pm 0.017^{\mathrm{C}}$ & $0.23 \pm 0.010^{\mathrm{F}}$ & $0.44 \pm 0.013^{\mathrm{C}}$ \\
\hline$v s$ & $v s$ & $v s$ & $v s$ & $v S$ & $v s$ \\
\hline$(150-3-30)$ & $(150-4-15)$ & $(200-3.5-25)$ & $(250-3-15)$ & $(200-3.5-25)$ & $(250-4-30)$ \\
\hline $0.42 \pm 0.020^{\mathrm{C}}$ & $0.34 \pm 0.005^{\mathrm{E}}$ & $0.47 \pm 0.015^{\mathrm{A}}$ & $0.47 \pm 0.012^{\mathrm{AB}}$ & $0.47 \pm 0.015^{\mathrm{A}}$ & $0.45 \pm 0.019^{\mathrm{BC}}$ \\
\hline$(250-3-30)$ & $(150-3-30)$ & $(150-3-30)$ & $(150-3-30)$ & $(150-4-15)$ & $(250-4-30)$ \\
\hline $0.44 \pm 0.013^{\mathrm{C}}$ & $0.42 \pm 0.020^{\mathrm{C}}$ & $0.42 \pm 0.020^{\mathrm{C}}$ & $0.42 \pm 0.020^{\mathrm{C}}$ & $0.34 \pm 0.002^{\mathrm{D}}$ & $0.45 \pm 0.019^{\mathrm{BC}}$ \\
\hline $\begin{array}{c}v s \\
(\mathbf{2 0 0}-3.5-25)\end{array}$ & $\begin{array}{c}v S \\
(250-3-30)\end{array}$ & $\begin{array}{c}v s \\
(\mathbf{2 0 0}-\mathbf{3 . 5}-\mathbf{2 5})\end{array}$ & $\begin{array}{c}v S \\
(150-4-30)\end{array}$ & $\begin{array}{c}v S \\
(\mathbf{2 5 0}-4-15)\end{array}$ & $\begin{array}{c}v s \\
(\mathbf{2 0 0}-\mathbf{3 . 5}-\mathbf{2 5})\end{array}$ \\
\hline $0.47 \pm 0.015^{\mathrm{A}}$ & $0.44 \pm 0.013^{\mathrm{B}}$ & $0.47 \pm 0.015^{\mathrm{A}}$ & $0.30 \pm 0.004^{\mathrm{E}}$ & $0.23 \pm 0.010^{\mathrm{F}}$ & $0.47 \pm 0.015^{\mathrm{A}}$ \\
\hline
\end{tabular}

Comparisons shown are only where the changes were significant $(\mathrm{p} \leq 0.05)$. The values in the table are means of organic acid concentrations $(\mathrm{g} / \mathrm{L})$ and standard deviation. Different uppercase superscript letters represent statistically significant differences in concentrations of the paired fermentation conditions. Paired fermentation conditions are sugars, $\mathrm{pH}$ and temperature (respectively in brackets). Those changes in fermentation conditions that resulted in increased pyruvic acid production are represented by red shading, while those that resulted in reduced production are represented by blue shading. The colour intensities represent the degree of variation between two conditions.

\& Ozbas, 2008). As in the current study, the authors also showed that yeast growth is uniquely dependent on both temperature and $\mathrm{pH}$.

\section{The impact of fermentation parameters on organic acid production}

In spite of the fact that multifactorial experiments are very complex due to the interactive nature of the parameters being investigated, our exploration of acid-condition relationships enabled us to pinpoint some specific drivers (individual and/ or multiple) of organic acid (pyruvic, acetic and succinic) production under fermentative conditions. The results highlight the fact that combinatorial changes to fermentation parameters may have additive, inverse or no impacts on organic acid levels compared to single factorial trends. These combinatorial impacts are also dependent on the specific strain employed (more so for pyruvic acid). Thus, for a given strain, there appear to be specific trends that can be inferred. This provides a measure of predictability for a given strain if its response to multifactorial changes have been determined experimentally. Moreover, from the data presented here, it is clear that strain-dependent differences are also drivers of wine acidity, making it difficult to derive representative multivariate comparisons and/or associations.

The impact of $\mathrm{pH}$ on pyruvic acid production in the current study is in line with the existing literature, as earlier studies suggest a link between $\mathrm{pH}$ and pyruvic acid levels during fermentation (Graham, 1979). The impact of $\mathrm{pH}$ and yeast strain on pyruvic acid production has also been noted previously (Rankine, 1967). A useful recommendation would be to monitor must $\mathrm{pH}$ carefully throughout fermentation, or at the different sampling times. This would enable a more thorough assessment of immediate $\mathrm{pH}$ impacts on pyruvic acid. The fact that commercial strains such as VIN13 and BM45 produced high pyruvic acid levels when $\mathrm{pH}$ was elevated, yet only under conditions of high sugar and high temperature, is a clear indication that changes to $\mathrm{pH}$ alone do not affect pyruvic acid production independently of other parameters. Furthermore, variations in the sugar content of the must resulted in major changes in the pyruvic acid levels of some strains. This outcome is not unexpected, as increased sugar availability would ultimately lead to more biomass formation, which could be associated with an increase in key anabolic intermediates such as pyruvic acid.

Changes to the prevailing fermentation conditions clearly influenced acetic acid production significantly. Apart from the fact that the impact of sugar stress on acetic acid production has been investigated in the production of botrytised wines (Bely et al., 2005), relatively little direct information exists regarding the impact of individual/multiple parameters such as sugar, temperature and $\mathrm{pH}$ on acetic acid levels in wine. While our results are not conclusive as to whether sugar alone plays a fundamental role in acetic acid concentration, a strong relationship between high fermentation sugars and 
high acetic acid levels in wine has previously been reported for $S$. cerevisiae (Bely et al., 2005; Ferreira et al., 2006).

There was also a notable but strain-specific impact of temperature on acetic acid production for both strains. It has previously been noted that higher temperatures may result in increased membrane fluidity, which allows metabolites to cross cell membranes more easily, resulting in high extracellular acetic acid.

Although higher initial must sugar concentrations have previously been reported to increase acetic acid production (Erasmus et al., 2004; Pigeau \& Inglis, 2005), we observed a decrease in acetic acid levels as a result of the combinatorial effects of high $\mathrm{pH}$, low temperature and high initial sugar content of the must. This is not a surprising observation, since variations in acetic acid production among yeast strains have been observed previously (Castellari et al., 1994).

The influence of temperature on succinic acid production was evident in some strains, as succinic acid production increased as a function of temperature. Similar to acetic acid, the relationship between extracellular succinic acid and higher temperatures may also be related to diffusion and/or temperature. Succinic acid production is clearly influenced in a complex manner by a combination of strain variation and fermentation conditions, which does not allow the extrapolation of clear strain effects or predictable responses to changes in fermentation conditions. However, the influence of specific parameters was evident for individual strains. While the results of this study investigate the influence of environmental factors on yeast-derived organic acid production, further work is required to assess the impact of additional factors such as yeast assimilable nitrogen (YAN), wine ageing, oligo-elements and anaerobic factors on these and other commercial wine yeast strains.

\section{CONCLUSIONS}

The data presented here clearly illustrate the importance of temperature, $\mathrm{pH}$ and sugar concentrations for organic acid evolution during fermentation. Higher temperature and initial sugar increased the rate of fermentation for both industrial strains investigated here. In terms of specific outcomes, pyruvic acid levels were significantly affected by (i) simultaneous changes in sugar, $\mathrm{pH}$ and temperature, and (ii) changes in sugar and temperature. Acetic acid concentrations, on the other hand, were affected by $\mathrm{pH}$ and combinatorial changes to sugar and temperature. Succinic acid production was influenced collectively by individual and/or combinatorial changes in $\mathrm{pH}$, sugar and fermentation temperature, but no clear and predictable trends could be extrapolated from the data. The exception was the impact of temperature, as increasing temperatures led to increases in succinic acid concentrations for both strains.

The study also makes the following recommendations based on the assessment of the impact of individual factors on acid production in synthetic grape must: (i) high initial sugars and temperature can be used to increase pyruvic acid levels for strain VIN13; (ii) moderate initial sugars (200 g/L) can be used for VIN13 fermentations when lower acetic acid levels are required in wines; (iii) higher fermentation temperatures $\left(30^{\circ} \mathrm{C}\right)$ can be used in order to obtain higher acetic acid levels in wines for both strains; and (iv) regardless of changes in the fermentation temperature or sugar content of the must, VIN13 is a higher producer of succinic acid in wines.

Overall, our findings confirm existing knowledge and, in addition, enabled us to identify individual and/ or multiple drivers of succinic, acetic and pyruvic acid production/release under different fermentation settings that may be encountered by winemakers in the industry. To our knowledge, this is the first report highlighting the effect of must composition and temperature on organic acid production using a multifactorial fermentation design implemented in conjunction with different wine yeast strains. As a practical outcome, the data can serve the development of fermentation guidelines with regard to acid management, or guide the design of additional, larger scale wine trials.

\section{LITERATURE CITED}

Agarwal, L., Isar, J., Meghwanshi, G.K. \& Saxena, R.K., 2007. Influence of environmental and nutritional factors on succinic acid production and enzymes of reverse tricarboxylic acid cycle from Enterococcus flavescens. Enz. Micr. Tech. 40(4), 629-636.

Aragon, P., Atienza, J. \& Climent, M.D., 1998. Influence of clarification, yeast type and fermentation temperature on the organic acid and higher alcohols of Malvasia and Muscatel Wines. Am. J. Enol. Vitic. 49(2), 211219.

Beltran, G., Novo, M., Guillamon, J.M., Mas, A. \& Rozes, N., 2008. Effect of fermentation temperature and culture media on the yeast lipid composition and wine volatile compounds. Int. J. Food Microbiol. 121, 169-177.

Bely, M., Masneuf-Pomarede, I. \& Dubourdieu, D., 2005. Influence of physiological state of inoculum on volatile acidity production by Saccharomyces cerevisiae during high sugar fermentation. J. Int. Sci. Vigne Vin 39, 191-197.

Bely, M., Sablayrolles, J.M. \& Barre, P., 1990. Automatic detection of assimilable nitrogen deficiencies during alcoholic fermentation in oenological conditions. J. Biosci. Bioeng. 70, 245-252.

Bisson, L.F. \& Block, D.E., 2002. Ethanol tolerance in Saccharomyces. In: Ciani, M. (ed.). Biodiversity and biotechnology of wine yeasts. Research Signpost, Kerala, India. pp. 85 - 98.

Boulton, R.B., Singleton, V.L., Bisson, L.F. \& Kunkee, R.E., 1996. Principles and practices of winemaking. Chapman and Hall, New York.

Box, G.E.P. \& Behnken, D.W., 1960. Some new three level designs for the study of quantitative variables. Technometrics 2, 455-475.

Castellari, L., Ferruzzi, M., Magrini, A., Giudici, P., Passarelli, P. \& Zambonelli, C., 1994. Unbalanced wine fermentation by cryotolerant vs. non-cryotolerant Saccharomyces strains. Vitis 33, 49-52.

Charoenchai, C., Fleet, G.H. \& Henschke, P.A., 1998. Effects of temperature, $\mathrm{pH}$, sugar concentration on the growth rates and cell biomass of wine yeasts. Am. J. Enol. Vitic. 49, 283-288.

D’Amato, D., Corbo, M.R., Del-Nobile, M.A. \& Sinigaglia, M., 2006. Effects of temperature, ammonium and glucose concentrations on yeast growth in a model wine system. Int. J. Food Sci. Tech. 41, 1152-1157.

Erasmus, D.J., Cliff, M. \& Van Vuuren H.J.J., 2004. Impact of yeast strain on the production of acetic acid, glycerol, and the sensory attributes of icewine. Am. J. Enol. Vitic. 55, 371-378. 
Eyeghe-Bickong, H.A., Alexandersson, E.O., Gouws, L.M., Young, P.R. \& Vivier, M.A., 2012. Optimisation of an HPLC method for the simultaneous quantification of the major sugars and organic acids in grapevine berries. J. Chromatogr. A. 885, 43-49.

Ferreira, J., Du Toit, M. \& Du Toit, W.J., 2006. The effects of copper and high sugar concentrations on growth, fermentation efficiency and volatile acidity production of different commercial wine yeast strains. Aust. J. Grape Wine Res. 12, 50-56.

Fleet, G.H. \& Heard, G.M., 1992. Yeasts growth during fermentation. In: Fleet, GH. (ed.) Wine Microbiology and Biotechnology. Harwood Academic Publishers, Chur, Switzerland. pp. 27 - 54.

Gao, C. \& Fleet, G.H., 1998. The effects of temperature and $\mathrm{pH}$ on the ethanol tolerance of the wine yeasts, Saccharomyces cerevisiae, Candida stellata and Kloeckera apiculate. J. Appl. Microbiol. 65, 405-410.

Graham, R.A., 1979. Influence of yeast strain and $\mathrm{pH}$ on pyruvic acid production during alcoholic fermentation. Am. J. Enol. Vitic. 30, 4318-320.

Kamzolova, S.V., Yusupova, A.I., Dedyukhina, E.G., Chistyakov, T.I., Kozyreva, T.M. \& Morgunov, I.G., 2009. Synthesis of succinic acid by yeasts. Food Technol. Biotech. 47, 144-152.

Lafon-Lafourcade, S., 1983. Wine and brandy. In: Rehm, H.J. \& Reed, G. (eds.). Food and feed production with microorganisms. Biotechnol. J. 5, 81-163.

Lambrechts, M.G. \& Pretorius, I.S., 2000 .Yeast and its importance in wine aroma - A review. S. Afr. J. Enol. Vitic. 21, 97-129.

Lee, P.C., Lee, W.G., Lee, S.Y. \& Chang, H.N., 1999. Effects of medium components on the growth of Anaerobiospirillum succiniciproducens and succinic acid production. Process Biochem. 35, 49-55.

Liu, D., Zhang, H., Xu, B. \& Tan, J., 2014. Influence of fermentation temperature and source of enzymes on enological characteristics of rice wine. J. Inst. Brew. 120(3), 231-237.

Mato, I., Suárez-Luque, S. \& Huidobro, J.F., 2005. A review of the analytical methods to determine organic acids in grape juices and wines. Food. Res. Int. $38,1175-1188$.

Orlic, S., Arroyo-Lopez, F.N., Huic-Babic, K., Lucilla, I., Querol, A. \& Barrio, E., 2010. A comparative study of the wine fermentation performance of Saccharomyces paradoxus under different nitrogen concentrations and glucose/fructose ratios. J. Appl. Microbiol. 108, 73-80.

Pigeau, G.M. \& Inglis, D.L., 2005. Yeast metabolic implications of icewine fermentation. Am. J. Enol. Vitic. 56, 418-430.

Pigeau, G.M., Bozza, E., Kaiser, K. \& Inglis, D.L., 2007. Concentration effect of Riesling icewine juice on yeast performance and wine acidity. J. Appl. Microbiol. 103, 1691-1698.
Rankine, B.C., 1967. Influence of yeast strain and $\mathrm{pH}$ on pyruvic acid content of wines. J. Sci. Food. Agric. 18, 41-44.

Remize, F., Roustan, J.L., Sablayrolles, J.M., Barre, P. \& Dequin, S., 1999. Glycerol overproduction by engineered Saccharomyces cerevisiae wine yeast strains leads to substantial changes in by-product formation and to a stimulation of fermentation rate in stationary phase. Appl. Environ. Microbiol. 65, 143-149.

Ribereau-Gayon, P., Glories, Y., Maujean, A. \& Dubourdieu, D., 2006 ( $2^{\text {nd }}$ ed.). Handbook of enology, Volume 2: The chemistry of wine stabilization and treatments. John Wiley \& Sons, Ltd., Chichester, England.

Rossouw, D., Naes, T. \& Bauer, F.F., 2008. Linking gene regulation and the exo-metabolome: A comparative transcriptomics approach to identify genes that impact on the production of volatile aroma compounds in yeast. BMC Genomics 9, 530-548.

Samuelov, N.S., 1988. Kinetics and regulation of 3-lactamase formation in methylotrophic bacterium. Biotechnol. Bioeng. 31, 125-129.

Serra, A., Strehaiano, P. \& Tallandier, P., 2005. Influence of temperature and $\mathrm{pH}$ on Saccharomyces bayanus var. uvarum growth; impact of a wine yeast interspecific hybridization on these parameters. Int. J. Food Microbiol. 104, 257-265.

Shannon, P., Markie, A., Ozier, O., Baliga, N.S., Wang, J.T., Ramage, D., Amin, N., Schwikowski, B. \& Ideker, T., 2003. Cytoscape: A software environment for integrated models of biomolecular interaction networks. Genome Res. 13(11), 2498-2504.

Shimazu, Y. \& Watanabe, M., 1981. Effects of yeast strains and environmental conditions on formation of organic acids in must fermentations. Ferm. Technol. 59, 27-32.

Shiraishi, M., Fujishima, H. \& Chijiwa, H., 2010. Evaluation of table grape genetic resources for sugar, organic acid and amino acid composition of berries. Euphytica 174, 1-13.

Soga, T. \& Ross, G.A., 1997. Capillary electrophoretic determination of inorganic and organic anions using 2,6-pyridinedicarboxylic acid: Effect of electrolyte's complexing ability. J. Chrom. A. 767, 223-230.

Thoukis, G., Ueda, M. \& Wright, D., 1965. The formation of succinic acid during alcoholic fermentation. Am. J. Enol. Vitic. 16(1), 1-8.

Torija, M.J., Rozes, N., Poblet, M., Guillamon, J.M. \& Mas, A., 2001. Yeast population dynamics in spontaneous fermentations: Comparison between two different wine-producing areas over a period of three years. Antonie Leeuwenhoek 79, 345-352.

Yalcin, S.K. \& Ozbas, Z.Y., 2008. Effects of $\mathrm{pH}$ and temperature on growth and glycerol production kinetics of two indigenous wine strains of Saccharomyces cerevisiae from Turkey. Bra. J. Microbiol. 39, 325-332. 